\title{
Thrombopoietin activates a STAT5-like factor in hematopoietic cells
}

\section{C.Pallard, F.Gouilleux' ${ }^{1}$, L.Bénit, L.Cocault, M.Souyri, D.Levy², B.Groner'1, S.Gisselbrecht and I.Dusanter-Fourt ${ }^{3}$}

U363 INSERM, ICGM, Hopital Cochin, 27 rue du Faubourg St Jacques, 75014 Paris, France, ${ }^{1}$ Institute for Experiment Cancer Research, Tumor Biology Center, Breisacher Strasse 117, D-79106 Freiburg, Germany and ${ }^{2}$ New York University Medical Center, Department of Pathology, 550 First Avenue, New York, USA

${ }^{3}$ Corresponding author

Thrombopoietin (TPO) is a newly cloned cytokine which is the major regulator of circulating platelet levels, acting on both proliferation and differentiation of megakaryocytes. We have investigated the ability of TPO to activate the JAK/STAT pathway in megakaryocytic cell lines. We used either the granulocyte-macrophage colony-stimulating factor (GM-CSF)- and/or erythropoietin (EPO)-dependent UT7 cell line in which the murine TPO receptor (mumpl) had been transfected (mumpl-UT7 transfectants) or the MO7E and DAMI cells which express endogenous human TPO receptors. We demonstrated that TPO activates the kinase JAK2 and a STAT5-like transcriptional factor but not STAT1, STAT2, STAT3 or STAT4, in a very rapid and transient manner. In order to better ascertain the specificity of the activation of STAT5-related factor by TPO, we investigated the effect of other cytokines/ growth factors. Both GM-CSF and EPO activated the STAT5-like factor. In contrast, neither interferon (IFN)- $\gamma$ nor the mitogenic stem cell factor (SCF) activated STAT5, although IFN- $\gamma$ did activate STAT1 in those cells. The hematopoietic DNA binding activity related to STAT5 was identified as a p97 tyrosinephosphorylated protein band which exhibited identical gel mobility to the mammary STAT5. Because v-mpl, a truncated form of the TPO receptor c-mpl, was shown to be oncogenic, we tested the activity of $v-\mathrm{mpl}$ on STAT5 and found STAT5 constitutively activated in two different $\mathrm{v}$-mpl-expressing cells, the transiently transfected Cos7 cells and the stable v-mpl-UT7 transfectants. Overall, our data indicate that STAT5 is widely expressed in hematopoietic cells and activated by a number of cytokines, including TPO, GM-CSF and EPO, but not by IFN- $\gamma$ or SCF.

Key words: hematopoiesis/signaling/STATs/thrombopoietin

\section{Introduction}

Thrombopoietin (TPO) is the major regulator of circulating platelet levels. The existence of this cytokine had been suspected for a long time, but it was only recently cloned. This glycoprotein was shown to stimulate both murine and human megakaryocytopoiesis and to increase platelet production in vivo (Bartley et al., 1994; de Sauvage et al., 1994; Kaushansky et al., 1994; Lok et al., 1994; Wendling et al., 1994). TPO exhibits significant homology with erythropoietin (EPO), the main regulator of red blood cell levels. The TPO receptor, the proto-oncogene c-mpl, is a member of the cytokine receptor superfamily that includes the receptors for EPO, granulocyte-macrophage colonystimulating factor (GM-CSF), granulocyte colonystimulating factor (G-CSF), growth hormone (GH), prolactin (PRL), interleukin (IL)-2-IL7 and others (Bazan, 1990; Cosman et al., 1990). In humans, expression of c-mpl appears to be restricted to CD34 ${ }^{+}$cells and to cells of megakaryocytic lineage (Methia et al., 1993; Debili et al., 1994). c-mpl was first isolated as an oncogene (v-mpl) being transduced as a truncated receptor in the envelope gene of the myeloproliferative leukemia retrovirus (MPLV) (Souyri et al., 1990). The proto-oncogene is characterized by the presence of two cytokine motifs in its extracellular domain, in contrast to $\mathrm{v}$-mpl which has lost nearly all the extracellular sequence of the protooncogene except the 43 juxtamembrane amino acids (Souyri et al., 1990; Vigon et al., 1992, 1993; Skoda et al., 1993). In vitro, expression of $\mathrm{v}-\mathrm{mpl}$ in hematopoietic cells induces growth factor-independent proliferation, suggesting that this truncated receptor functions as a constitutively activated receptor (Wendling et al., 1989; Bénit et al., 1994).

Biochemical events triggered by ligand-activated cytokine receptors-including the related and well known cytokine EPO-are the induction of tyrosine phosphorylation of the receptor itself and of a number of transducing molecules such as shc or the phosphatidyl inositol 3 kinase and other cellular proteins. The activation of several tyrosine kinases as well as serine/threonine kinases such as c-raf, B-raf and MAP kinase has been reported (reviewed in Kishimoto et al., 1994). A recent signal transduction pathway which involves Janus tyrosine kinases (JAK) and proteins known as signal transducers and activators of transcription (STATs) has recently been found to be regulated by a number of hematopoietic cytokine receptors (reviewed in Darnell et al., 1994; Ihle et al., 1994).

JAK proteins are cytoplasmic kinases of molecular weight $\sim 130 \mathrm{kDa}$ lacking both $\mathrm{SH} 2$ and SH3 domains. Four JAKs are presently known: TYK2, JAK1, JAK2 (reviewed in Ihle et al., 1994) and the new JAK3 (Johnston et al., 1994; Witthuhn et al., 1994). By genetic analysis, members of this tyrosine kinase family were shown to be absolutely required for ligand-activated interferon (IFN) receptors to signal the regulation of gene expression and to transmit the activation of the specific STATs (rewiewed in Pellegrini and Schindler, 1993; Darnell et al., 1994). These kinases were also shown to be activated by a number of cytokines including EPO, GH, GM-CSF, PRL, G-CSF, IL-3, IL-6-related cytokines, IL-2, -4, -7, -9, and 
to bind to their respective receptors (reviewed in Ihle et al., 1994; Johnston et al., 1994; Miyazaki et al., 1994; Russell et al., 1994). JAKs were shown to be strictly required for transducing the proliferative signal of EPO, IL-3 or IL-2 (Miyazaki et al., 1994; Zhuang et al., 1994).

The STATs are cytosolic transcriptional factors which contain $\mathrm{SH} 2$ and SH3 domains and are tyrosine phosphorylated following ligand activation. They dimerize (homo- or heterodimerization) and translocate into the nucleus where they bind and activate specific DNA sequences (reviewed in Pellegrini and Schindler, 1993; Shuai et al., 1994; Darnell et al., 1994). Six STATs are now characterized. The first STATs originally identified (p91-STAT1 and p113-STAT2) were shown to be involved in the IFN signaling pathway. STAT1 and STAT2 are components of the IFN-stimulated gene factor 3 (ISGF3) (Fu, 1992) which binds to IFN $\alpha$-stimulatable response elements (ISRE) upstream of IFN- $\alpha$-inducible genes (Schindler et al., 1992). STAT1 but not STAT2 is involved in the IFN- $\gamma$ signaling pathway, forming tyrosine-phosphorylated homodimers which bind to IFN- $\gamma$ activation sequences (GAS) (Shuai et al., 1994). STAT3 was identified as a transcriptional factor induced by IL-6 in hepatocytes (Akira et al., 1994), while STAT4 was discovered by virtue of its homology to STAT1 with no known activator so far (Yamamoto et al., 1994; Zhong et al., 1994). The MGF-STAT5 was identified by its ability to activate the transcription of casein genes under the control of PRL (Wakao et al., 1994) while STAT6 was identified as an IL4-activated STAT in monocytic cells (Hou et al., 1994). In addition, a number of cytokine-responsive proteins seem to be related to STATs based on tyrosine phosphorylation and related DNA binding specificity, without further precise identification (Kotanides and Reich, 1993; Larner et al., 1993; Ruff-Jamison et al., 1993; Sadowski et al., 1993, Silvennoinen et al., 1993; David et al., 1994; Finbloom et al., 1994; Gilmour and Reich, 1994; Meyer et al., 1994; Sliva et al., 1994).

STAT5, originally identified as a transcriptional factor activated by PRL in the lactating mammary gland, was shown to be strictly required for the induction of transcription of milk caseins. However, it has been reported to be more widely expressed, being present in spleen and thymus as well as in other tissues (Wakao et al., 1994). STAT5 is activated by the JAK2 tyrosine kinase in vitro (Gouilleux et al., 1994). This transcriptional factor recognizes a specific palindromic sequence, TTCxxxGAA (Standke et al., 1994; Gouilleux et al., 1995) which is found in the $\beta$-casein promoter but also in a number of promoters of genes other than mammary genes, such as genes coding for the rat serine protease inhibitor 2.1-2.2, human interstitial cell adhesion molecule (ICAM), high affinity immunoglobin $\mathrm{G} F \mathrm{c}$ receptor gene ( $\mathrm{Fc} \gamma \mathrm{R} 1)$, interferon consensus sequence binding protein (ICSBP), rat $\alpha 2$-macroglobulin and IFN regulatory factor- 1 (IRF-1) (Yoshimura and Oka, 1989; Harada et al., 1994; Pine et al., 1994; Sliva et al., 1994). These findings suggest that STAT5 could play other role(s) than solely induction of milk proteins in the mammary gland. Preliminary data indicated that STAT5 was activated by PRL not only in mammary epithelial cells but also in PRL receptor (PRL-R)-transfected hematopoietic cells (BAF-3) (Pallard et al., submitted).

In this study, we have investigated the ability of TPO

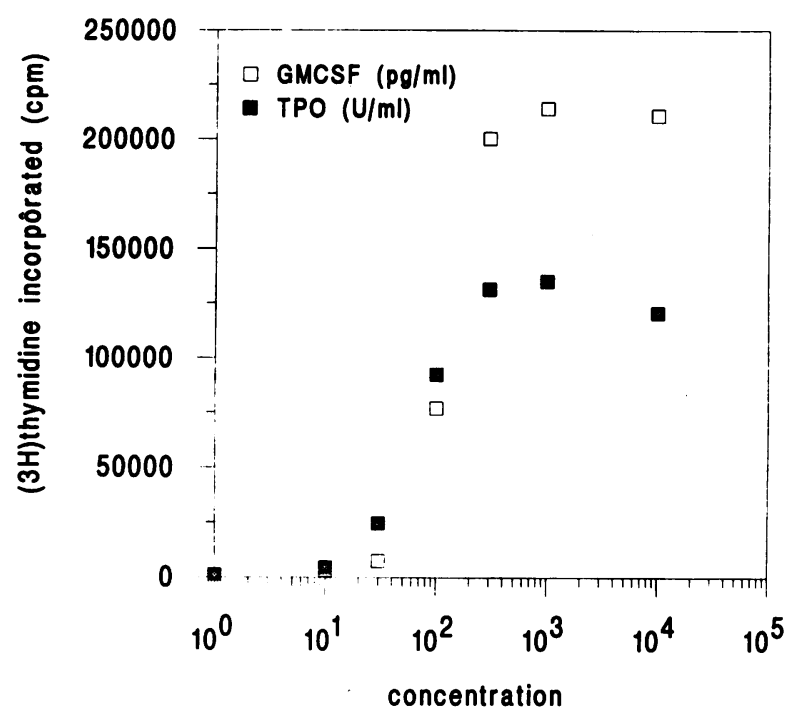

Fig. 1. TPO induces the proliferation of mumpl-UT7 cells. Cells $\left(5 \times 10^{3}\right.$ /point) were incubated with the indicated concentration of either murine TPO $(\mathrm{U} / \mathrm{ml})$ or GM-CSF $(\mathrm{pg} / \mathrm{ml})$ for $36 \mathrm{~h}$ and $\left[{ }^{3} \mathrm{H}\right]$ thymidine added for the next $4 \mathrm{~h}$. The amount of $\left[{ }^{3} \mathrm{H}\right]$ thymidine incorporated in the cells was determined (c.p.m.).

to activate the JAK/STAT pathway in hematopoietic cells. We used either the GM-CSF- and/or EPO-dependent UT7 cell line in which we introduced the murine TPO receptor (mumpl) and established clones (mumpl-UT7) that proliferate in the presence of TPO, or MO7E and DAMI cells expressing their endogenous human TPO receptors. We demonstrated that TPO activates the JAK2 kinase and a STAT5-like transcriptional factor rapidly and transiently, but not STAT1, STAT2, STAT3 or STAT4. In addition, because v-mpl was shown to be oncogenic, we tested its activity on STAT5 and found that v-mpl constitutively activates STAT5 in two different cellular contexts.

\section{Results}

\section{TPO induces proliferation and tyrosine phosphorylations on various proteins including JAK2}

UT7 is a human leukemic cell line derived from a patient with a megakaryoblastic leukemia. It is stricly dependent on the presence of GM-CSF or EPO for its growth and survival (Komatsu et al., 1991). We introduced the murine mpl cDNA (mumpl) cloned in the pJZenTKneo retroviral vector (Chang and Johnson, 1989) in UT7 cells maintained with GM-CSF and selected for neomycin resistance. As shown in Figure 1, mumpl-transfected cells (mumpl-UT7) were able to proliferate in response to murine TPO with a half-maximal rate obtained at $100 \mathrm{U} / \mathrm{ml}$. Similarly to the parental cells, mumpl-UT7 cells also proliferate in the presence of GM-CSF. However, even using high doses of TPO, the cells did not reach the same proliferative rate as the one obtained in the presence of optimal doses of GM-CSF, due to the very low level of TPO receptors expressed in these cells selected for their neomycin resistance only (not shown). These mumpl-UT7 cells were deprived of growth factors for $18 \mathrm{~h}$ and next incubated with TPO for $2-30 \mathrm{~min}$. Total cellular phosphotyrosyl proteins were immunoprecipitated and resolved on PAGE. 


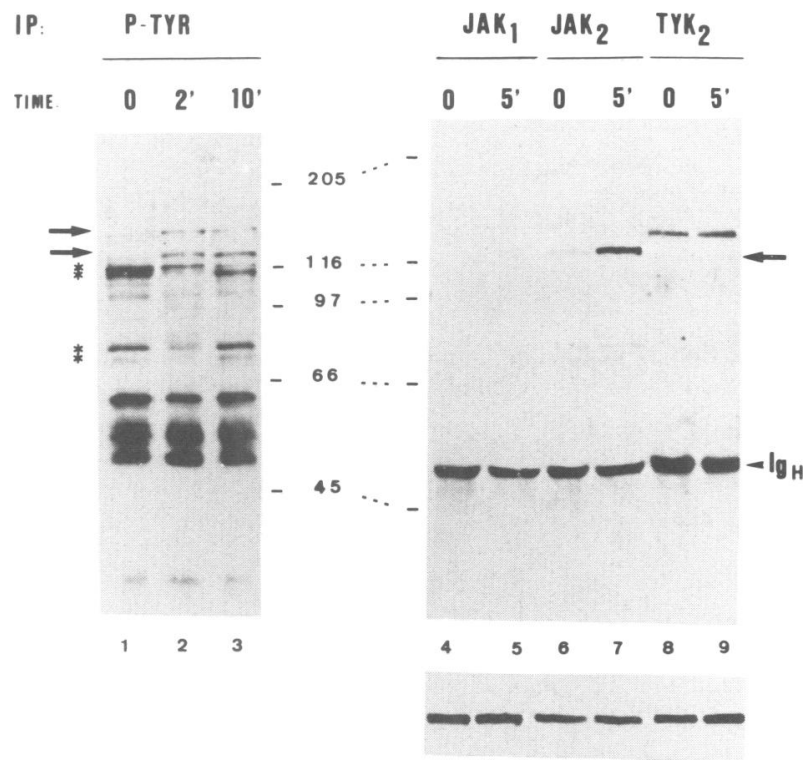

Fig. 2. TPO induces the tyrosine phosphorylations of cellular proteins including JAK2. mumpl-UT7 cells $\left(1-2 \times 10^{7} /\right.$ lane $)$ were incubated with TPO $(1000 \mathrm{U} / \mathrm{ml})$ for the indicated times and total tyrosinephosphorylated proteins (lanes 1-3) or JAK1, JAK2 and TYK2 were immunoprecipitated and analyzed by PAGE and Western blotting using a monoclonal anti-phosphotyrosine antibody. Molecular weight markers are indicated in the middle $(\mathrm{kDa})$. The major bands whose tyrosine phosphorylations were increased or decreased by TPO treatment are shown by large arrows and stars, respectively. Immunoglobulin $\mathrm{G}$ heavy chains present in immunoprecipitates are indicated $\left(\operatorname{Ig}_{\mathrm{H}}\right)$. (Bottom) The blot was stripped and further incubated with anti-JAK1 (lanes 4-5), anti-JAK2 (lanes 6-7) and anti-TYK2 (lanes 8-9).

As shown in Figure 2 lanes 1-3, TPO induced the rapid tyrosine phosphorylation of a number of proteins (see arrows) as well as rapid dephosphorylation of other bands (see stars). Interestingly, among those, one band at $\mathrm{M}_{\mathrm{r}}$ 130000 was rapidly and transiently tyrosine phosphorylated. This was reminiscent of members of the JAK family. These kinases were immunoprecipitated with anti-JAK antibodies from cells treated with TPO and analyzed by Western blotting using anti-phosphotyrosine antibodies. Among the four JAKs presently known, only JAK1, JAK2 and TYK2 were expressed in UT7 cells. JAK3 was not detected in UT7 cells although, using the same anti-JAK3 antibody, we found JAK3 present in Jurkat cells (data not shown). As indicated in Figure 2 lanes 4-9, TPO induced the rapid tyrosine phosphorylation of JAK2 but not of JAK1 or TYK2.

\section{TPO, GM-CSF and EPO induce a similar and transient DNA binding activity in hematopoietic cells}

STAT proteins act downstream of JAK kinases in regulating gene expression. Therefore electrophoretic mobility shift assays (EMSA) were performed with oligonucleotides known to bind STATs. Since STAT5 is highly expressed in spleen and thymus (Wakao et al., 1994) and is a direct substrate for JAK2 in vitro (Gouilleux et al., 1994), we focused our research on STAT5. We first used the STAT5 binding sequence from the $\beta$-casein promoter (Wakao et al., 1994). As shown in Figure 3, nuclear extracts prepared from TPO-treated mumpl-UT7 cells (lanes 2-6)

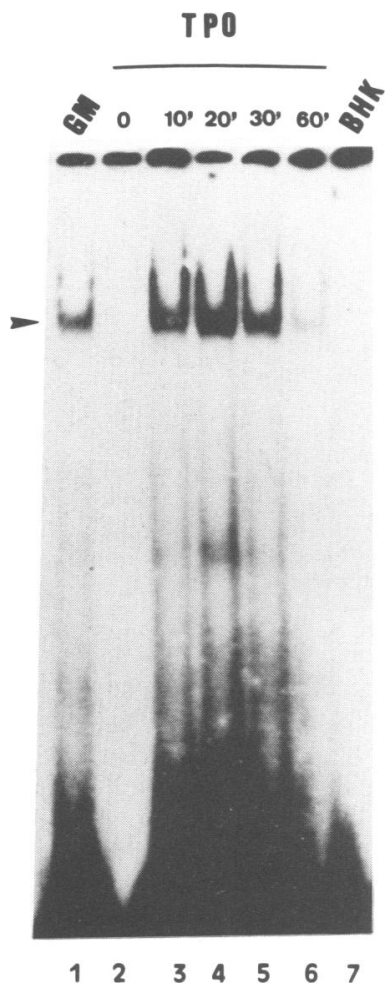

Fig. 3. TPO induces the activation of a DNA binding complex. mumpl-UT7 cells $\left(2 \times 10^{5}\right.$ /point) were incubated with TPO (1000 U/ml, lanes 2-6) for the indicated times, or with GM-CSF (lane 1) $(2.5 \mathrm{ng} / \mathrm{ml})$ for $30 \mathrm{~min}$, or with medium from untransfected BHK cells (lane 7) (volume equivalent to $1000 \mathrm{U} / \mathrm{ml}$ ) for $30 \mathrm{~min}$ Nuclear extracts were prepared and analyzed in band shift assays (EMSA) using the $\beta$-casein promoter STAT5 binding site as a probe. Shifted complexes are indicated by an arrow. The radioactivity at the bottom of the gel corresponds to free probe.

possessed DNA binding activity with the $\beta$-casein probe. The shifted oligonucleotide complex resolved as a single band in EMSA detected as soon as 1 min after TPO treatment (not shown). This complex was relatively transient, becoming almost absent after 60 min of TPO incubation (lane 6). Because the TPO used was a serumfree culture medium from TPO-transfected BHK cells, mumpl-UT7 cells were incubated with medium from untransfected BHK cells as a control: no DNA binding activity was found with the $\beta$-casein probe (lane 7).

To assess further the induction of a STAT5-like DNA binding activity in TPO-treated cells, the EMSA experiments were extended to another STAT5 DNA binding sequence, the GAS of the IRF-1 (Harada et al., 1994; Pine et al., 1994). This IRF-1 GAS contains the palindromic TTCxxxGAA motif that was shown to be required for STAT5 binding (Standke et al., 1994; Gouilleux et al., 1995). As shown in Figure 4 lanes 1-8, TPO-treated cells possessed a DNA binding activity with the IRF-1 GAS oligonucleotide. The complex bound to IRF-1 GAS migrated with exactly the same mobility as the complex bound to the $\beta$-casein probe and was induced with similar kinetics (not shown). Concentration analyses of the TPOactivated DNA binding complexes revealed that they were induced at concentrations as low as $20 \mathrm{U} / \mathrm{ml}$ (lanes 3-8). This TPO concentration is similar to the concentration of TPO required for cells to start proliferating (see Figure 1). 


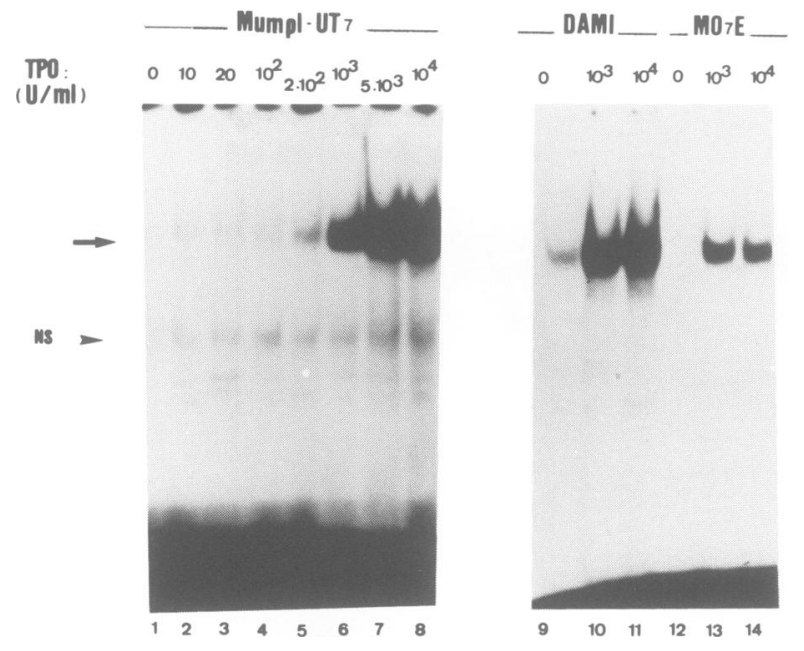

Fig. 4. TPO activates a DNA binding activity in various megakaryocytic cell lines. mumpl-UT7 cells (1-8), DAMI cells (lanes 9-11) or MO7E cells (lanes 12-14) were incubated with TPO for 20 min at the concentrations indicated. Nuclear extracts were analyzed by EMSA using an IRF-1 GAS probe.

The nuclear extracts positive for DNA binding activity with the $\beta$-casein probe possessed the same binding activity with the IRF-1 GAS probe, i.e. kinetics, concentrationdependence and migration patterns of the nuclear complexes; we used either probe in the next experiments.

We had already observed that the human megakaryocytic cell lines DAMI and MO7E expressed an endogenous 84 $\mathrm{kDa}$ mpl protein on their cell surface (Debili et al., 1994 and data not shown). To extend the data obtained on the mumpl-UT7 cells, DAMI or MO7E cells were incubated in the presence of murine TPO. Analysis of the nuclear extracts by EMSA indicated that TPO induced a DNA binding activity with the IRF-1 probe in both cells (Figure 4, lanes 9-14). The complexes migrated exactly as the complex induced in TPO-treated mumpl-UT7 cells (lanes $1-8)$. Similar results were obtained with the $\beta$-casein probe (not shown), indicating that TPO-dependent activation of a STAT5-like DNA binding activity was not restricted to the transfected cell line but also occurred in human cells expressing endogenous c-mpl.

Nuclear extracts from GM-CSF- and EPO-treated mumpl-UT7 cells were also prepared. Both cytokines induced a similar rapid and transient DNA binding complex with the $\beta$-casein probe (Figure 5), which migrated at the same position and with mobility identical to the TPO-induced complex (compare Figure 3, lanes 1 and 3).

\section{TPO, GM-CSF and EPO induce the activation of a p97 STAT5-like protein in hematopoietic cells}

To investigate further the TPO-induced DNA binding complex, competition studies were performed with a variety of GAS-containing sequences. In these experiments, nuclear extracts from TPO-treated cells were coincubated with a 50-fold molar excess of the unlabeled competitor oligonucleotide and the labeled probe. The TPO-induced complex was competed effectively by the IRF-1 GAS (Figure 6, lane 6), the $\beta$-casein (lane 2) and the FC $\gamma \mathrm{R}$ GAS (lane 8) oligonucleotides, partly by the acute phase responsive element (APRE) (lane 3), weakly by the Ly6E GAS (lane 9) but not by the guanylate

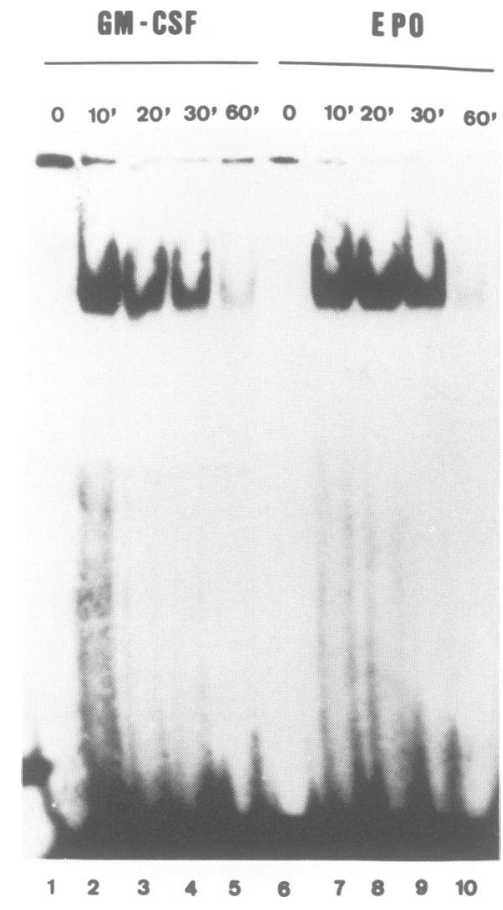

Fig. 5. GM-CSF and EPO activate a similar DNA binding activity in mumpl-UT7 cells. Cells were treated with GM-CSF $(2.5 \mathrm{ng} / \mathrm{ml})$ or EPO $(10 \mathrm{U} / \mathrm{ml})$ for the indicated times. Nuclear extracts were analyzed by EMSA using the $\beta$-casein probe.

binding protein (GBP) GAS (lane 4), ISRE (lane 5) or sis-inducible element (SIE) (lane 7). These last three oligonucleotides do not contain any related TTCxxxGAA motif required for STAT5 binding. Competition studies were also done using the $\beta$-casein probe and nuclear extracts from lactating mammary gland or from Cos 7 cells co-expressing the mammary STAT5 and the PRL receptor (Gouilleux et al., 1994, 1995) and identical results were obtained, indicating that the DNA binding activity induced in the TPO-treated mumpl-UT7 cells or by PRL in mammary epithelial cells had similar DNA binding specificities.

To extend the above data, supershift experiments were performed with antibodies raised against the different STATs (except STAT6) to determine whether any of these STATs were actually present in the TPO-induced complexes. As shown in Figure 7, the supershift assays demonstrated that the TPO-induced complex did not react with either STAT1, STAT2, STAT3 or STAT4 antisera: the presence of the antisera in the binding reactions did not alter the mobility of the complexes (lanes 10-13). However, the presence of a STAT5 antiserum or a pan-STAT antiserum reactive to all known STATs (Raz et al., 1994) (lanes 14-15) did alter the apparent mobility of the DNA binding complex, indicating the presence of an immunologically related STAT5 protein in the TPOinduced extracts. Identical results were obtained in nuclear extracts from cells treated with GM-CSF (lanes 3-8) or EPO (not shown).

No data have been reported on the expression of a STAT5 protein in hematopoietic cells. Therefore we characterized further the DNA binding factor induced by TPO. In addition, as activation of STATs is known to depend on tyrosine phosphorylation (Darnell et al., 1994; 


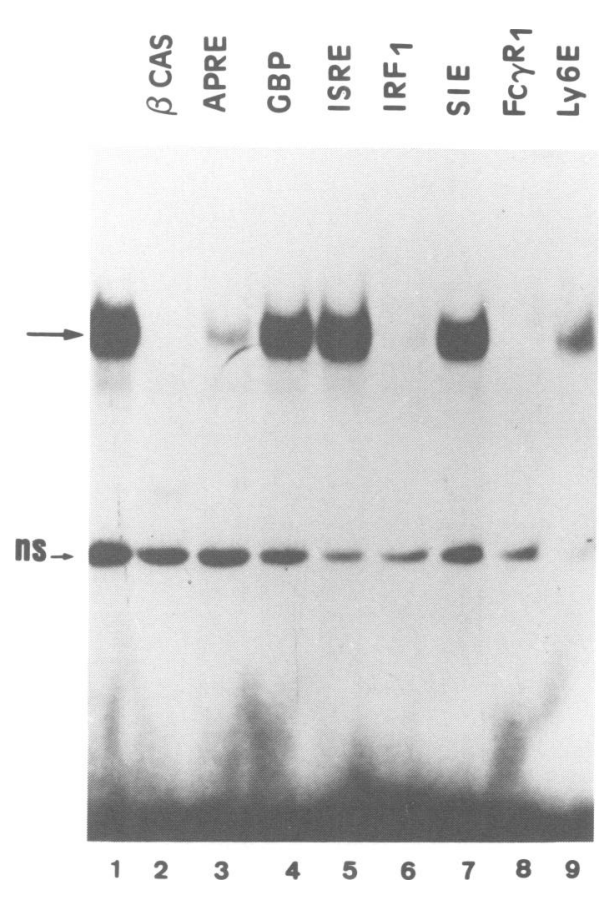

Fig. 6. TPO-induced DNA binding protein binds to a precise subset of GAS elements. Nuclear extracts from TPO-treated mumpl-UT7 cells were analyzed by EMSA with the IRF-1 probe in the presence of a 50 -fold excess of the indicated oligonucleotides. The shifted complexes are shown by a large arrow. One non-specific band which was not displaced by an excess of unlabeled probe was visible in this particular experiment (ns).

Gouilleux et al., 1994), the tyrosine phosphorylation of the hematopoietic STAT5-like protein was examined. Nuclear extracts from TPO-, GM-CSF- (Figure 8) or EPOtreated (not shown) mumpl-UT7 cells were incubated with Sepharose beads coupled to multimerized STAT5 binding sites (Wakao et al., 1994). Bound proteins were eluted, analyzed by SDS-PAGE, blotted onto filters and developed with either anti-phosphotyrosine antibodies (Figure 8, lanes 1-2 and 5-6) or anti-STAT5 antiserum (lanes 3-4). A single tyrosine-phosphorylated band, of $M_{r}$ $97 \mathrm{kDa}$, was identified in nuclear extracts from TPO(lane 2), GM-CSF- (lane 6) or EPO- (not shown) treated cells that bound STAT5 binding oligonucleotide. Similarly, a single band reacted with the anti-STAT5 antiserum (lane 4). The p97 band exhibited the same migration mobility as the mammary STAT5 expressed in transfected Cos7 cells (Gouilleux et al., 1994, 1995). This band was totally absent in untreated cells (lanes $1,3,5$ ). The doublet band at $\sim 50-60 \mathrm{kDa}$ appearing in lane 6 was often detected in unstimulated cells and should correspond to non-specific binding on the Sepharose beads. These results indicate that hematopoietic cells express a protein highly related, if not identical, to the sheep mammary STAT5.

\section{IFN- $\gamma$ and SCF do not activate a STAT5-like protein}

In order to ascertain better the specificity of STAT5 activation in TPO-, GM-CSF- and EPO-treated cells, we investigated the effect of other cytokines/growth factors. Mumpl-UT7 cells, like the parental ones, express IFN- $\gamma$ receptors. These cells did not proliferate in the presence of IFN- $\gamma$. Nuclear extracts from IFN- $\gamma$-treated cells were assayed for the presence of DNA binding activity using

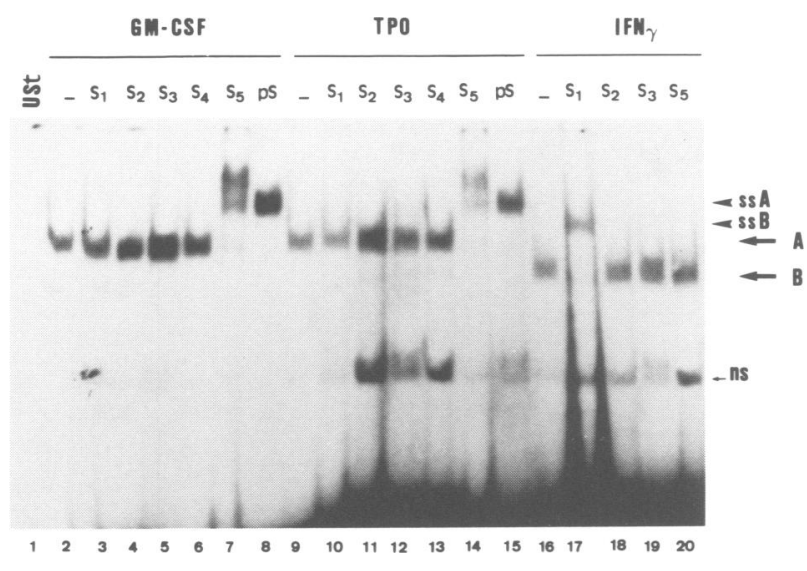

Fig. 7. TPO and GM-CSF, but not IFN- $\gamma$, activate a STAT5-like factor which binds IRF-1 probe. Nuclear extracts from mumpl-UT7 cells treated either with no factor (Ust, lane 1), GM-CSF $(2.5 \mathrm{ng} / \mathrm{ml}$, lanes $2-8)$, TPO (1000 U/ml, lanes 9-15) or IFN- $\gamma(1000 \mathrm{U} / \mathrm{ml}$, lanes 16-20) for $20 \mathrm{~min}$ were analyzed by EMSA in the absence (-) or presence of the indicated antibodies. S1, S2, S3, S4, S5 and pS are abbreviations for antibodies against STAT1, STAT2, STAT3, STAT4, STAT5 and pan-STAT, respectively. ssA and ssB indicate the supershifted complexes from complex $A$ and $B$, respectively, and $n s$ is the non-specific band.

the same IRF-1 GAS probe as before. As shown in Figure 7 lanes 16-20, IFN- $\gamma$ induced a DNA binding activity with the IRF-1 GAS (complex B) which migrated faster than the one induced by TPO or GM-CSF (complex A), indicating that a different DNA binding complex was induced. Supershift assays showed that this complex reacted with STAT1 antiserum (lane 17) and the panSTAT antiserum (not shown), but not with STAT2, STAT3 (lanes 18-19), STAT4 (not shown) or STAT5 antisera (lane 20), indicating that IFN- $\gamma$ only induced STAT1 in UT7 cells. Similar results were obtained with the $\beta$-casein probe using extracts from either mumpl or parental UT7 cells.

We extended these experiments further. A subclone of the parental UT7 cells that proliferated in the presence of stem cell factor (SCF) with kinetics similar to GM-CSF or EPO had been established. Half-maximal proliferation rate was obtained at $\sim 2 \mathrm{ng} / \mathrm{ml} \mathrm{SCF}$, while full proliferation was obtained at $10 \mathrm{ng} / \mathrm{ml} \mathrm{SCF}$ (V.Duprez and P.Mayeux, personal communication). Nuclear extracts from these cells treated with GM-CSF, EPO, TPO or SCF were tested for DNA binding activity with the $\beta$-casein probe. As shown in Figure 9, although GM-CSF- or EPO-treated cells induced a STAT5-like activity (lanes 1-5), SCF did not (lanes 8-11). Concentrations as high as $50 \mathrm{ng} / \mathrm{ml}$ of SCF were tested: SCF did not induce STAT5 activation (lane 11), even after shorter (10 min) or longer incubation (60 min) (not shown). Those cells did not proliferate in the presence of TPO and, as expected, TPO did not activate STAT5 (lanes 6-7).

\section{$v$-mpl constitutively activates STAT5}

Since v-mpl is an oncogenic form of mumpl, we tested whether the constitutively active receptor permanently activates STAT5. We performed transient co-transfection assays in the $\operatorname{Cos} 7$ cells which contain undetectable levels of STAT5. However, when introducing the mammary STAT5 cDNA together with the PRL-R (Gouilleux et al., 


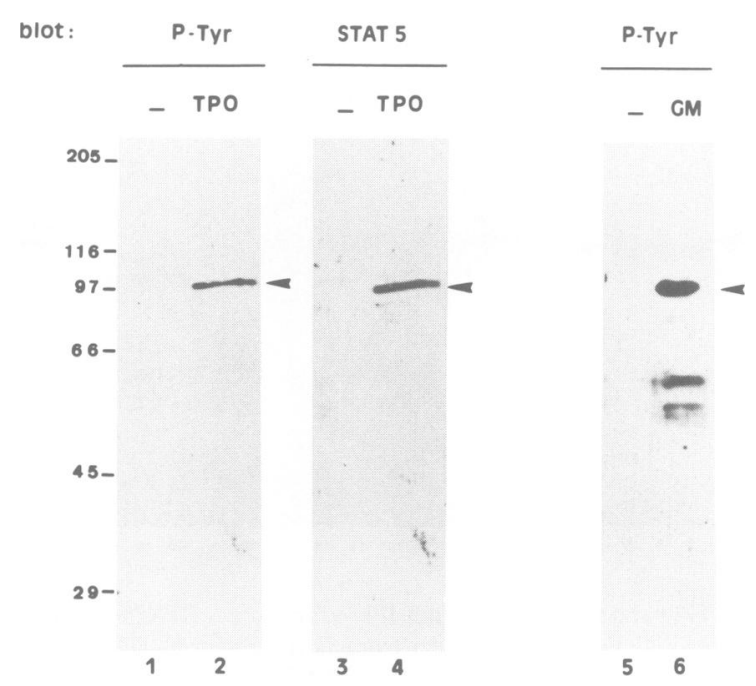

Fig. 8. Purification and identification of the TPO- and GMCSFinduced STAT5-like protein in the mumpl-UT7 cells. Nuclear extracts from $3 \times 10^{7}$ cells treated with either no factor $(-$, lanes $1,3,5)$, TPO $(1000 \mathrm{U} / \mathrm{ml}$, lanes 2,4$)$ or GM-CSF $(2.5 \mathrm{ng} / \mathrm{ml}$, lane 6) for $20 \mathrm{~min}$ were incubated with multimerized STAT5 binding oligonucleotides coupled to Sepharose beads. Bound proteins were eluted and analyzed by SDS-PAGE followed by blotting with the indicated antibodies and detection by chemiluminescence. Molecular weight markers are indicated on the left of the figure.

1994), GH-R or EPO-R (Gouilleux et al., 1995), the liganddependent activation of STAT5 was clearly detected. v-mpl cDNA was introduced in Cos7 cells, with or without the mammary STAT5 cDNA, and the presence of a DNA binding activity was tested with the $\beta$-casein or IRF-1 GAS probe. As shown in Figure 10A lanes 5-6, v-mpl did not activate any endogenous STAT protein that bound the $\beta$-casein or IRF-1 GAS oligonucleotide. However, in the v-mpl and STAT5 co-transfected Cos cells, the mammary STAT5 was clearly activated in the absence of TPO (lanes 3-4). As expected, the transfection of the mumpl cDNA together with mammary STAT5 triggered the activation of STAT5 only in the presence of TPO (lanes 1-2).

To strengthen these data, we extended these experiments further. $\mathrm{v}$-mpl had been subcloned previously in an expression vector, introduced in the parental UT7 cells, and cells expressing $\mathrm{v}$-mpl were selected as stable transfectants. These v-mpl-expressing UT7 cells (v-mpl-UT7) were able to grow in the absence of added growth factor and no longer required the presence of GM-CSF or EPO for their survival (Bénit et al., 1994). Nuclear extracts from two clones expressing $\mathrm{v}$-mpl (clone 2 and clone 8) were assayed for DNA binding activity with the $\beta$-casein probe and compared with extracts from mumpl-UT7 cells. In contrast to unstimulated mumpl-UT7 cells (Figure 10B, lane 7), in the absence of added growth factor v-mplUT7 cells contained a DNA binding activity with the $\beta$-casein probe (lanes 1-6). This complex migrated with exactly the same mobility as the complex induced in TPOtreated mumpl-UT7 cells (lane 8). Supershift experiments with anti-STAT5 or anti-STAT1 antibodies indicated that $\beta$-casein-bound complexes from v-mpl-UT7 cells contained an activated STAT5-like protein (lanes 2 and 5) but no STAT1 (lanes 3 and 6). As mentioned above, such a complex was never detected in mumpl-UT7 cells in the

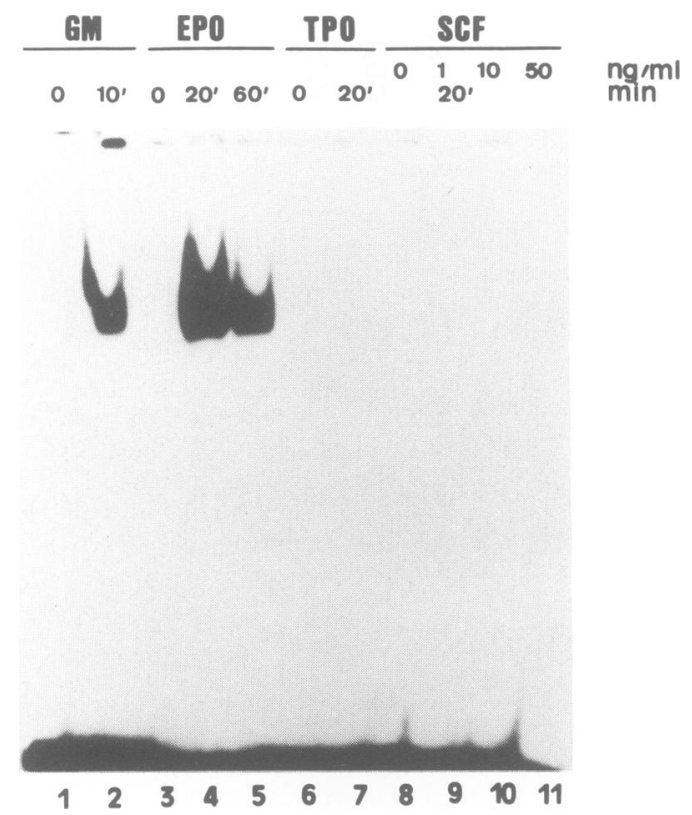

Fig. 9. The mitogenic factor SCF does not induce the activation of a STAT5-like factor. Nuclear extracts from a subclone of the parental UT7 cells (UT7-S) were prepared from GM-CSF $(2.5 \mathrm{ng} / \mathrm{ml}$, lanes 1-2)-, EPO (10 U/ml, lanes 3-5)-, TPO (1000 U/ml, lanes 6-7)or SCF (1-50 ng/ml, lanes 8-11)-treated cells and were analyzed by EMSA using the $\beta$-casein probe.

absence of TPO, even after prolonged exposure of the gels (see Figure 4 lane 1 versus lane 8).

\section{Discussion}

The present data demonstrate that in hematopoietic cells the TPO-R (c-mpl) activates a DNA binding complex that was indistinguishable from the PRL-induced mammary STAT5 previously identified, in that: (i) the TPO-induced DNA binding complex bound to STAT5 binding sites derived from the mammary $\beta$-casein and from the IRF-1 promoter; (ii) the DNA binding complex was competed by the same oligonucleotides used to displace the interaction between the mammary STAT5 and the $\beta$-casein promoter, i.e. by FC $\gamma$ RI GAS but not by ISRE, GBP GAS or SIE; (iii) the DNA binding complex was reactive in supershift assays with anti-STAT5 antibody but not with antibodies to STAT1, STAT2, STAT3 or STAT4; (iv) the DNA binding protein was tyrosine phosphorylated, migrated as a single band of $97 \mathrm{kDa}$, as does the mammary STAT5, and reacted with STAT5 antiserum in Western blot; (v) these results were found in several human TPO-responsive cells (mumpl-UT7, MO7E, DAMI cells) expressing exogenous murine or endogenous human $\mathrm{c}-\mathrm{mpl}$, indicating that the activation of the hematopoietic STAT5 by TPO was not merely a characteristic of a particular cell line. Moreover, using the IRF-1 GAS oligonucleotide that contained STAT1 and STAT3 binding sites, we did not detect any activation of STAT1, STAT2, STAT3 or STAT4 by TPO. In addition, c-mpl activated the mammary STAT5 when both were co-transfected in Cos7 cells. To our knowledge, this is the first demonstration for the activation of a STAT by TPO. Although the hematopoietic STAT5-like factor activated by TPO is presently indistinguishable from the 


$$
\text { CoS cells }
$$

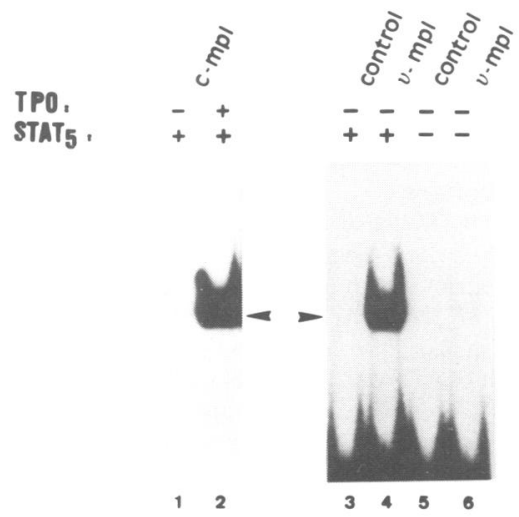

B.

UT-7 cells
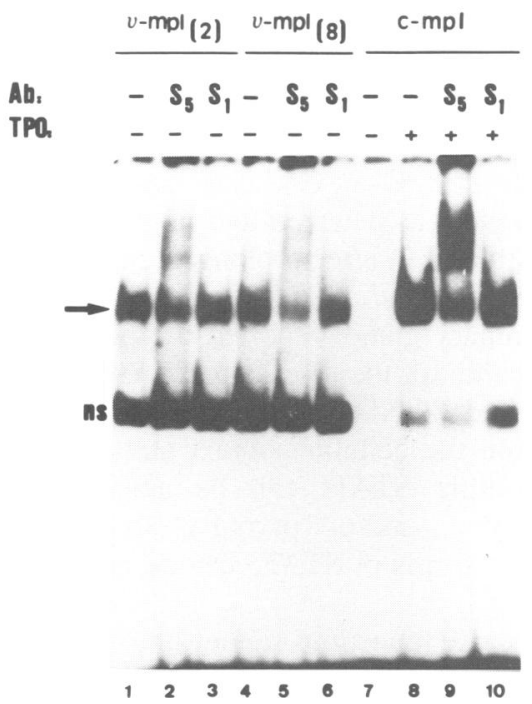

Fig. 10. v-mpl constitutively activates STAT5. (A) Cos cells were co-transfected with c-mpl (lanes 1-2) or v-mpl (lanes3-6) in the presence (+) or absence (-) of mammary STAT5 expression vector. After $48 \mathrm{~h}$, cells were incubated with or without TPO (1000 U/ml) for $20 \mathrm{~min}$, as indicated. Nuclear extracts were analyzed by EMSA using the $\beta$-casein probe. Shifted complexes are indicated by arrows. (B) UT7 cells expressing v-mpl (clone 2, lanes 1-3, or clone 8, lanes 4-6) or mumpl (lanes 7-10) were incubated with (+) or without (-) TPO (1000 U/ml) for $20 \mathrm{~min}$. Nuclear extracts were analyzed by EMSA with the $\beta$-casein probe in the absence $(-)$ or presence $(+)$ of an excess of the indicated antibodies (Ab). S1 and S5 are abbreviations for antibodies against STAT1 or STAT5, respectively. Shifted complexes are indicated by an arrow; ns, non-specific band.

PRL-induced mammary STAT5, we cannot exclude that it could be encoded by a new STAT5-like gene.

Our experiments have also established that the activation of the hematopoietic STAT5 by TPO was shared by GM-CSF and EPO, but not with IFN- $\gamma$, although in the same cells IFN- $\gamma$ triggered the activation of STAT1 which binds to the same GAS-containing probe used (IRF-1 GAS). Therefore, although multiple STATs are present in a cell, only one or a few will specifically be activated by a precise ligand-activated receptor, introducing a first level of specificity in cytokine signal transduction pathways. These results are in agreement with others on the detection of tyrosine phosphorylation of undefined STATs by EPO (Finbloom et al., 1994; Yamamoto et al., 1994), GM-CSF (Larner et al., 1993), IL-2 (Beadling et al., 1994), GH (Sliva et al., 1994) or PRL (O’Neal and Yu-Lee, 1994) in hematopoietic cells. All these reports used various oligonucleotide probes (Fc $\gamma$ RI GAS, IRF-1 GAS, Spi1 GAS) to detect the induction of DNA binding activities. Interestingly, all these GAS oligonucleotide sequences did contain the palindromic STAT5 binding motif TTCxxxGAA. Since we also demonstrated the activation of a STAT5-like protein by PRL, EPO and IL-3 in the hematopoietic murine BAF-3 cell line (Pallard et al., submitted), we suggest that the unknown STATs activated in the above reports may all be related to STAT5. If this is confirmed, it would indicate that activation of STAT5 is not solely induced by JAK2-activating ligands (TPO, GM-CSF, IL-3, EPO, PRL, GH), but could also occur through the activation of JAK3/JAK1 (IL-2) (Beadling et al., 1994; Johnston et al., 1994; Miyazaki et al., 1994).

Our data suggested that the three cytokines TPO, GMCSF and EPO, activate similar JAK/STATs pathway in the same cell, since all activate JAK2 and not JAK1 (this report; Ihle et al., 1994) and all three activate STAT5 and not STAT1-4 (this report; Larner et al., 1993; Finbloom et al., 1994; Yamamoto et al., 1994). Since these three cytokines induce cell proliferation of the UT7 cells but trigger different differentiation programs (Hermine et al., 1992; and unpublished data), our results would be consistent with a role of JAK2/STAT5 in cell proliferation rather than in cell differentiation. This hypothesis is further strengthened by our findings that PRL and IL-3-which mainly allow the hematopoietic BAF-3 cells to proliferate-also activate STAT5 in BAF-3 cells, and by the possible activation of STAT5 by a number of other cytokines (see above). However, SCF did not activate STAT5 in a UT7 subclone, although these cells proliferate at exactly the same rate and had the same doubling time in the presence of SCF or EPO. Therefore, if the activation of STAT5 is responsible for the induction of mitosis by the above cytokines, an alternative pathway triggered by SCF should exist. Whether this alternative pathway is activated by other growth factors and/or involves other unidentified STATs or unrelated transcriptional factors remains to be established. Because SCF binds to a receptor with intrinsic tyrosine kinase activity, it seems worth knowing whether other growth factors acting through tyrosine kinase receptors do activate STAT5 or not.

Alternatively, differential activation(s) of the hematopoietic STAT5 leading to a transcriptional factor with variable transactivating potencies could be triggered by different cytokines independently of only tyrosine phosphorylation; serine/threonine phosphorylations are already known to be essential for the activity of a number of transcriptional factors (Hunter and Karin, 1992). Lastly, the common activation of STAT5 by TPO, GM-CSF and EPO might be associated with differential activation(s) of other interacting transcriptional factors forming specific 
transcriptional complexes leading to differential regulation of gene transcription.

In contrast to Finbloom et al. (1994) or Larner et al. (1993) using the human erythroleukemic cell line TF1 and human monocytes, we only detected one band of tyrosine-phosphorylated nuclear proteins associated with the GAS-beads from EPO- or GM-CSF-treated UT7 cells: only a $97 \mathrm{kDa}$ band was detected and no proteins at 80 $84 \mathrm{kDa}$ were visible even after prolonged exposure of the Western blots. Wakao et al. (1994), using nuclear extracts from sheep mammary gland, reported the purification of two proteins bound to the $\beta$-casein STAT5-responsive element, of 92 and $84 \mathrm{kDa}$ respectively. This suggests that, depending on the cellular context and the cytokine used, either multiple STATs can be activated and/or different proteolytic, and/or partially spliced, and/or partially processed forms of STAT5 can be expressed and triggered.

Our findings raise questions about the gene targets whose expression might be modified by the activated STAT5 in hematopoietic cells. A good candidate for regulating the cell cycle could be the IRF-1 gene. The IRF-1 gene contains a STAT5 binding site/GAS and encodes a DNA binding factor that recognizes a sequence in the promoter of some genes activated by IFNs (Harada et al., 1994; Pine et al., 1994). However, IRF-1 was also reported to be involved in growth regulation: its activity was tightly regulated during the cell cycle or during differentiation (Abdollahi et al., 1991; Harada et al., 1993; Kirchhoff et al., 1993; Tanaka et al., 1994). Loss of the IRF-1 gene is a frequent occurrence in human myelodysplastic syndromes and therefore it may function as an antioncogene (Willman et al., 1993). In addition, expression of the IRF-1 gene is stimulated by a variety of cytokines including IL-1, IL-2, IL-3, IL-6, leukemia inhibitory factor, tumor necrosis factor, PRL and IFNs (Levy et al., 1988; Fujita et al., 1989; Abdollahi et al., 1991; Schwarz et al., 1992; O'Neal and Yu-Lee, 1994). Taken together, these observations suggested that IRF-1 may be a critical tumor suppressor involved in the regulation of the normal cell cycle. Whether the induction of IRF-1 is involved in the cellular response to TPO, GM-CSF and EPO is currently under investigation.

Our data also indicated that STAT5 protein can be constitutively activated in cells expressing the oncogenic receptor v-mpl, either in the non-hematopoietic Cos7 cells transiently transfected with $\mathrm{v}$-mpl or in the hematopoietic UT7 cells stably transfected with v-mpl (v-mpl-UT7). This is the first evidence of a permanent activation of a transcriptional factor from the STAT family by an oncogene. Since v-mpl was shown to induce proliferation without blockage of differentiation processes in MPLVinfected hematopoietic cells, the constitutive activation of STAT5 further strengthens a possible role of STAT5 in mitogenesis and/or inhibition of apoptosis. Whether or not this activation occurred directly remains to be determined. This constitutive activation of STAT5 should provide a simple assay to determine which region(s) of $v$-mpl are critically involved in STAT5 activation.

Overall, our data demonstrate that STAT5-like proteins are ubiquitous factors which are expressed in hematopoietic cells and activated by a number of cytokines including TPO, GM-CSF and EPO, but not by IFN- $\gamma$ or SCF. Moreover, these transcriptional factor can be constitutively activated in cells expressing the oncogenic form of a cytokine receptor such as v-mpl.

\section{Materials and methods}

\section{Cell culture}

Parental (Komatsu et al., 1991) or mumpl-transfected UT7 cells and MO7E cells (Avanzi et al., 1988) were maintained in $\alpha$-medium supplemented with $10 \%$ fetal calf serum (FCS) and $2.5 \mathrm{ng} / \mathrm{ml}$ recombinant GM-CSF. The cells were arrested in a quiescent state by washing three times in phosphate-buffered saline (PBS) and replacing in Iscove medium supplemented with transferrin $(20 \mu \mathrm{g} / \mathrm{ml})$ and bovine serum albumin $(0.4 \%)$ in the absence of cytokine for $18 \mathrm{~h}$, as described by DusanterFourt et al. (1994). Alternatively, cells were maintained in 10\% FCS in the absence of cytokine for $18 \mathrm{~h}$ prior induction. Similar results were obtained under both conditions. Cells were induced in the presence of the indicated cytokine/growth factor for $1-60 \mathrm{~min}$ at $37^{\circ} \mathrm{C}$. A subclone of the parental UT7 cells which had acquired the ability to proliferate in response to SCF with a similar doubling time to that in response to GM-CSF or EPO had been established (UT7-S). This clone was maintained in $\alpha$-medium-10\% FCS supplemented with either EPO (20 $\mathrm{U} / \mathrm{ml}$ ) or SCF $(50 \mathrm{ng} / \mathrm{ml})$. DAMI cells (Greenberg et al., 1988) were maintained in $\alpha$-medium with $10 \%$ FCS and were deprived of serum for $6 \mathrm{~h}$ prior to stimulation with TPO. UT7 cells expressing v-mpl (clones 2 and 8) (Bénit et al., 1994) were maintained in $\alpha$-medium with $10 \%$ FCS. Cos 7 cells were maintained in Dulbecco's modified minimal medium with $10 \%$ FCS.

Murine TPO was kindly provided by Zymogenetics Inc. (Seattle, USA) and obtained as a serum-free medium from stably transfected BHK cells expressing TPO (Lok et al., 1994). Ten units was defined as the amount of TPO inducing half-maximal proliferation of BAF-3 cells stably expressing the transfected murine mpl. As a control, serum-free medium from untransfected BHK cells was also used. Recombinant EPO was from Boerhinger Mannhein, SCF was obtained from Amgen and recombinant human IFN- $\gamma$ was a gift from Roussel Uclaf.

\section{Plasmids}

Murine mpl cDNA (Vigon et al., 1992) or v-mpl were subcloned into the retroviral vectors pJZen TkNeo (Chang and Johnson, 1989) or pBabeNeo (Morgenstern and Land, 1990), as described (Bénit et al., 1994). UT7 cells were electroporated $\left(10^{7}\right.$ cells) in the presence of $50 \mu \mathrm{g}$ of the mumpl-pJZenTkNeo plasmid or $50 \mu \mathrm{g}$ of the v-mpl-pBabeNeo plasmid and were selected for their resistance to $800 \mu \mathrm{g} / \mathrm{ml} \mathrm{G} 418$ during 20 days. $\operatorname{Cos} 7$ cells were transfected using the DEAE-dextran method. $5 \mu \mathrm{g}$ of the pBabeNeo containing either mumpl or $\mathrm{v}-\mathrm{mpl}$ and $5 \mu \mathrm{g}$ of the pXM-STAT5 (Gouilleux et al., 1994) were used for each transfection. Cos 7 cells were collected 2 days later, as described (Gouilleux et al., 1994).

\section{Immunoprecipitation and Western blot}

Cells were lysed in 1\% NP-40 buffer and extracts were immunoprecipitated as described (Dusanter-Fourt et al., 1994). The antibodies used were directed against the following: JAK1 C-terminal fusion protein (Witthuhn et al., 1994) (gift from A.Ziemiecki); JAK2 C-terminal peptide (aa 758-776 of murine JAK2, Upstate Biotechnology Inc.); JAK3 C-terminal peptide (aa 1105-1124 of human JAK3, Santa Cruz Biotechnology Inc); TYK2 fusion protein (Barbieri et al., 1994) (gift from S.Pellegrini, Paris); STAT1 N-terminal domain (anti-ISGF3 p91/p84 monoclonal antibody, Transduction Laboratories, UK); STAT2 (gift from C.Shindler, New York); STAT3 C-terminal peptide (30C, gift from D.Levy, New York University Medical Center) (Raz et al., 1994); STAT4 C-terminal peptide (C-20, Santa Cruz Biotechnology Inc.); STAT5 N-terminal fusion protein containing amino acids 6-160 of sheep mammary STAT5 (Gouilleux et al., 1995); STAT3 N-terminal peptide which recognizes all STATs presently known (Riaz et al., 1994) (30N, named thereafter pan-STAT, gift from D.Levy); and anti-phosphotyrosine monoclonal 4G10 (gift from B.Drucker, Portland). Anti-STAT5 antiserum was shown to be specific for STAT5, with no recognition of STAT1, 2 , 3 or 4 (Gouilleux et al., 1995). Immunoreactive bands were visualized by chemiluminescence (Amersham).

\section{Electrophoretic mobility shift assays}

Nuclear extracts were prepared by a brief lysis of the cells in a mild buffer $(50 \mathrm{mM}$ Tris- $\mathrm{HCl} \mathrm{pH} 7.9,10 \mathrm{mM} \mathrm{KCl}, 0.2 \% \mathrm{NP}-40,10 \%$ 
glycerol, $1 \mathrm{mM}$ EDTA, $1 \mathrm{mM}$ DTT, $1 \mathrm{mM}$ PMSF, $0.1 \mathrm{mM} \mathrm{Na}_{2} \mathrm{VO}_{4}$ ) followed by extraction of the pelleted nuclei with a hypertonic buffer containing $400 \mathrm{mM} \mathrm{NaCl}, 20 \%$ glycerol, $20 \mathrm{mM}$ HEPES pH 7.9, $10 \mathrm{mM}$ $\mathrm{KCl}, 1 \mathrm{mM}$ EDTA, $1 \mathrm{mM}$ PMSF, $1 \mathrm{mM} \mathrm{Na} 2 \mathrm{VO}_{4}$. The extracts were centrifuged at $20000 \mathrm{~g}$ for $5 \mathrm{~min}$ and supernatants were immediatly frozen in liquid nitrogen and stored at $-80^{\circ} \mathrm{C}$ before use. The oligonucleotide sequences used were derived from the bovine $\beta$-casein promoter (5'-AGATTTCTAGGAATTCAAATC- $3^{\prime}$ ) and the human IRF-1 GAS (5'-GATCCATTTCCCCGAAATGA- $\left.3^{\prime}\right)$. Probes were end-labeled with $\left[\gamma_{-}{ }^{32} \mathrm{P}\right] \mathrm{ATP}$ and 40000 c.p.m. were used per reaction $(16 \mathrm{fmol})$. Extracts (from $1 \times 10^{5}$ cells/point) were incubated for $30 \mathrm{~min}$ at $4^{\circ} \mathrm{C}$ in $20 \mu \mathrm{l}$ of binding buffer with $2 \mu \mathrm{g}$ poly $(\mathrm{dI}-\mathrm{dC})$. Complexes were separated on $4 \%$ non-denaturating polyacrylamide gels in $0.25 \times \mathrm{TBE}$ and detected by autoradiography. For competition assays, unlabeled oligonucleotides ( $\alpha 2$-macroglobulin-APRE, 5'-GATCCTTCTGGGAATTCCTA-3'; GBP GAS, 5'-AAGTACTTTCAGTTTCATATTACTCTAAATA-3'; interferonstimulated Ly6E GAS, 5'-CATGTTATGCATATTCCTGTAAGTG-3'; ISG15 ISRE, 5'-GATCGGGAAAGGGAAACCGAAACTGAAGCC-3'; Fc $\gamma$ R 1 GAS, 5'-GTATTTCCCAGAAAAGGAAC-3'; SIE from the c-fos promoter, 5'-GTCGACAGTTCCCGTCAATC-3') were added at $50 \times$ molar excess with the probe. For supershifts assays, nuclear extracts were incubated with an excess of the indicated antibodies and the probe.

DNA binding proteins were isolated from nuclear extracts of 20 $30 \times 10^{6}$ cells. Extracts were first checked for the presence of STAT5like complexes by EMSA, then diluted and incubated at $4^{\circ} \mathrm{C}$ for $45 \mathrm{~min}$ in binding buffer [ $10 \mathrm{mM}$ Tris $\mathrm{pH} 7.5,1 \mathrm{mM}$ EDTA, $1 \mathrm{mM}$ DTT, $50 \mathrm{mM} \mathrm{NaCl}, 0.1 \% \mathrm{NP}-40,5 \%$ glycerol, $20 \mu \mathrm{g}$ poly $(\mathrm{dI}-\mathrm{dC})]$ in the presence of double-stranded 5 ' oligonucleotides from the STAT5 binding site of the $\beta$-casein promoter coupled to Sepharose beads, as described (Wakao et al., 1994). Complexes were washed twice in binding buffer and separated by SDS-PAGE. Bound proteins were detected by Western analysis as above.

\section{Acknowledgements}

We gratefully acknowledge Dr S.Pellegrini, Dr G.Jolivet and all our colleagues for critically reading the manuscript and stimulating discussions. We thank Dr G.Courtois for providing the v-mpl-UT7 clones, Dr V.Duprez and P.Mayeux for providing the UT-S subclone, Dr Don Foster (Zymogenetics, Seattle) for providing murine thrombopoietin, Dr B.Drucker (Portland, USA) for providing phosphotyrosine antibodies, Dr C.Schindler (New York, USA) for providing STAT2 antibodies, Dr A.Ziemiecki (Bern, Switzerland) for providing JAK1 antibodies, Dr S.Pellegrini (Paris, France) for Tyk2 antibodies and Terry Fox Laboratories for the pJZen TK vector. This study was supported by a grant from Association de Recherches pour le Cancer to I.DusanterFourt (1177-93), a grant from IFSBM to C.Pallard. I.Dusanter-Fourt is supported by the Institut National de la Recherche Agronomique.

\section{References}

Abdollahi,A., Lord,K.A., Hoffman-Liebermann,B. and Liebemann,D.A. (1991) Cell Growth Differ., 2, 401-407.

Akira,S. et al (1994) Cell, 77, 63-71.

Avanzi,G., Lista,P., Giouinazzo,B., Minlero,R., Saglio,G., Benetton,G., Coda,R., Cattoretti,G. and Pegoaro,L. (1988) Br. J. Haematol., 69, 359-368.

Barbieri,G., Velazquez,L., Scrobogna,M., Fellous,M. and Pellegrini,S. (1994) Eur. J. Biochem., 223, 427-435.

Bartley,T.D. et al. (1994) Cell, 77, 1117-1124.

Bazan,J.F. (1989) Proc. Natl Acad. Sci. USA, 87, 6934-6938.

Beadling,C., Guschin,D., Witthuhn,B.A., Ziemiecki,A., Ihle,J.N., Kerr,I.M. and Cantrell,D.A. (1994) EMBO J., 13, 5605-5615.

Bénit,L., Courtois,G., Charon,M., Varlet,P., Dusanter-Fourt,I. and Gisselbrecht,S. (1994) J. Virol., 68, 5270-5274.

Chang,Y. and Johnson,J. (1989) Int. J. Cell Cloning, 7, 264-266.

Cosman,D. Lyman,S.D., Idzerda,R.L., Beckmann,M.P., Park,L.S., Goodwin,R.G. and March,C.J. (1990) Trends Biochem. Sci., 15, 265-270.

Darnell,J.E., Kerr,I.M. and Stark,G.R. (1994) Science, 264, 1415-1420.

David,M., Petricoin,E.F.III, Igarashi,K., Feldman,G.M., Finbloom,D.S. and Larner,A.C. (1994) Proc. Natl Acad. Sci. USA, 91, 7174-7178.

Debili,N. et al. (1995) Blood, in press.

de Sauvage,F.J. et al. (1994) Nature, 369, 533-538.

Dusanter-Fourt,I. et al. (1994) EMBO J., 13, 2583-2591.
Finbloom,D. et al. (1993) Mol. Cell. Biol., 14, 2113-2118.

Fu,X. (1992) Cell, 70, 323-335.

Fujita,T., Reis,L.F., Watanabe,N., Kimura,Y. and Taniguchi,T. (1989) Proc. Natl Acad. Sci USA, 86, 9936-9940.

Gilmour,K.C. and Reich,N.C. (1994) Proc. Natl Acad. Sci. USA, 91, 6850-6854.

Gouilleux,F., Wakao,H., Mundt,M. and Groner,B. (1994) EMBO J., 13, $4361-4369$.

Gouilleux,F., Pallard,C., Dusanter-Fourt,I., Wakao,H., Haldosen,L.-A., Norstedt,G., Levy,D. and Groner,B. (1995) EMBO J., 14, 2005-2013.

Greenberg,S.M., Rosenthal,D.S., Greeley,T.A., Tantravahi,R. and Handin,R.I. (1988) Blood, 72, 1968-1972.

Harada,H., Kitagawa,M., Tanake,N., Yamamoto,H., Harada,K., Ishihara,M. and Taniguchi,T. (1993) Science, 259, 971-974.

Harada,H., Takahashi,E., Itoh,S., Harada,K., Hori,T.-A. and Taniguchi,T. (1994) Mol. Cell. Biol., 14, 1500-1509.

Hermine, O. et al. (1992) Blood, 80, 3060-3069.

Hou,J., Schindler,U., Henzel,W., Ho,T., Brasseur,M. and McKnight,S.L. (1994) Science, 265, 1701-1706.

Hunter,T. and Karin,M. (1992) Cell, 70, 375-387.

Ihle,J.N., Witthuhn,B.A., Quelle,F.W., Yamamoto,K., Thierfelder,W.E., Kreider,B.L. and Silvennoinen,O. (1994) Trends Biochem. Sci., 19, 222-227.

Johnston,J., Kawamura,M., Kirken,R.A., Chen,Y.-Q., Blake,T.B., Shibuya,K., Ortaldo,J.R., McVicar,D.W. and O'Shea,J.J. (1994) Nature, 370, 151-153.

Kaushansky,K. et al. (1994) Nature, 369, 568-570.

Kirchhoff,S., Schaper,F. and Hauer,H. (1993) Nucleic Acids Res., 21, 2881-2889.

Kishimoto,T., Taga,T. and Akira,S. (1994) Cell, 76, 253-262.

Komatsu,N. et al. (1991) Cancer Res., 51, 341-348.

Kotanides,H. and Reich,N.C. (1993) Science, 262, 1265-1267.

Larner,A.C., David,M., Feldman,G.M., Igarashi,K., Hackett,R., Webb,D., Sweitzer,S.M., Petricoin,E.F.III and Finbloom,D.S. (1993) Science, 261, 1730-1733.

Levy,D.E., Kessler,D.S., Pine,R., Reich,N., Darnell,J.E.,Jr (1988) Genes Dev., 2, 383-393.

Lok,S. et al. (1994) Nature, 369, 565-568.

Methia,N., Louache,F., Vainchenker,W. and Wendling,F. (1993) Blood, 82, 1395-1401.

Meyer,D., Campbell,G.S., Cochran,B.H., Argetsinger,L.D., Larner,A., Finbloom,D.S., Carter-Su,C. and Schwartz,J. (1994) J. Biol. Chem., 269, 4701-4704.

Miyazaki,T. et al. (1994) Science, 266, 1045-1047.

Morgenstern,J.P. and Land,H. (1990) Nucleic Acids Res., 18, 3587-3596. O'Neal,K. and Yu-Lee,L. (1994) J. Biol. Chem., 269, 26076-26082.

Pellegrini,S. and Schindler,C. (1993) Trends Biochem. Sci., 18, 338-342.

Pine,R., Canova,A. and Schindler,C. (1994) EMBO J., 13, 158-167.

Raz,R., Durbin,J.E. and Levy,D.E. (1994) J. Biol. Chem., 269, 2439124395.

Ruff-Jamison,S., Chen,K. and Cohen,S. (1993) Science, 261, 1733-1736.

Russell,S.M. et al. (1994) Science, 266, 1042-1045.

Sadowski,H.B., Shuai,K., Darnell,J.E. and Gilman,M.Z. (1993) Science, 261, 1739-1744.

Schindler,C., Shuai,K., Prezioso,V.R. and Darnell,J.E. (1992) Science, 257, 809-813.

Schwarz,L.A., Stevens,A.M., Hrachovy,J.A. and Yu-Lee,L.-Y. (1992) Mol. Cell. Endocrinol., 86, 103-110.

Shuai,K., Horvath,C.M., Huang,L.H., Quareshi,S.A., Cowburn,D. and Darnell,J.E. (1994) Cell, 76, 821-828.

Silvennoinen,O., Schindler,C., Schlessinger,J. and Levy,D.E. (1993) Science, 261, 1736-1739.

Skoda,R.C., Seldin,D.C., Chiang,M., Peichel,C.L., Vogt,T.F. and Leder,P. (1993) EMBO J., 12, 2645-2656.

Sliva,D., Wood,T.J., Schindler,C., Lobie,P.E. and Norstedt,G. (1994) J. Biol. Chem., 269, 26208-26214.

Souyri,M., Vigon,I., Penciolelli,J.F., Heard,J.M., TambourinP. and Wendling,F. (1990) Cell, 63, 1137-1147.

Standke,G., Meyer,V. and Groner,B. (1994) Mol. Endocrinol., 8, 469-477.

Tanaka,N. et al. (1994) Cell, 77, 829-839.

Vigon,I., Mornon,J.P., Cocault,L., Mitjavila,M., Tambourin,P., Gisselbrecht,S. and Souyri,M. (1992) Proc. Natl Acad. Sci. USA, 89, 5640-5644.

Vigon,I., Florindo,C., Fichelson,S., Guenet,J., Mattei,M., Souyri,M., Cosman,D. and Gisselbrecht,S. (1993) Oncogene, 8, 2607-2615.

Wakao,H., Gouilleux,F. and Groner,B. (1994) EMBO J., 13, 2182-2191. 
Wendling,F., Penciolleli,J.F., Charon,M. and Tambourin,P. (1989) Blood, 73, 1161-1167.

Wendling,F. et al. (1994) Nature, 369, 571-574.

Willman,C.L. et al. (1993) Science, 259, 968-971.

Witthuhn,B.A., Silvennoinen,O., Miura,O., Lai,K.S., Cwik,C., Liu,E.T. and Ihle,J. (1994), Nature, 370, 153-157.

Yamamoto,K., Quelle,F., Thierfelder,W., Kreider,B., Gilbert,D., Jenkins,N., Copeland,N., Silvennoinen,O. and Ihle,J.N. (1994) Mol. Cell. Biol., 14, 4342-4349.

Yoshimura,M. and Oka,T. (1989) Gene, 78, 267-275.

Zhong,Z., Wen,Z. and Darnell,J.E. (1994) Proc. Natl Acad. Sci. USA, 91, 4806-4810.

Zhuang,H., Patel,S.V., He,T.C., Sonsteby,S.K., Niu,Z. and Wojchowski,D.M. (1994) J. Biol. Chem., 269, 21411-21414.

Received on January 26, 1995; revised on March 16, 1995 